\title{
A-SA SOS: A Mobile- and IoT-based Pre-hospital Emergency Service for the Elderly and Village Health Volunteers
}

\author{
Kannikar Intawong ${ }^{1}$, Waraporn Boonchieng ${ }^{2}$ \\ Faculty of Public Health \\ Chiang Mai University \\ Chiang Mai, Thailand
}

\author{
Peerasak Lerttrakarnnon ${ }^{3}$ \\ Faculty of Medicine \\ Chiang Mai University \\ Chiang Mai, Thailand
}

\author{
Ekkarat Boonchieng ${ }^{4}$ \\ Faculty of Science \\ Chiang Mai University \\ Chiang Mai, Thailand
}

\author{
Kitti Puritat ${ }^{5}$ \\ Faculty of Humanities \\ Chiang Mai University \\ Chiang Mai, Thailand
}

\begin{abstract}
In Thailand, emergency illnesses are lifethreatening conditions that constitute serious health problems and quick access to definitive care can improve the survival rate of the elderly dramatically. Currently, the pre-hospital emergency medical services have limitations which prevent the treatment from getting to the accident site on time. In this research, we proposed the A-SA SOS application, a mobile-and IoT-based pre-hospital emergency service for the elderly. The system helps the elderly to send the request to the nearest village health volunteers via a mobile application and smart device. After reaching the elderly, the village health volunteers help carry out basic life support to increase the survival rate before sending the patients directly to the Emergency Management System (EMS) agency. To evaluate the system, we tested it for three months in the Sub-district of Suthep in Chiang Mai city. Finally, the incident report showed that the average time to reach the scene $(4.91 \pm 0.56)$ to help elderly patients was less than the standard criteria of an average 3 minutes.
\end{abstract}

Keywords-Pre-hospital emergency service; mobile healthcare; IoT-based healthcare system; elderly; healthcare volunteer

\section{INTRODUCTION}

Currently, Thailand has become an aging society. According to the Institute for Population and Social Research, Mahidol University [1], in 2018, there were approximately 11.7 million Thai people aged over 60 , accounting for 17.6 percent of the entire nation's population. It is extrapolated that the number of elderly will increase to 20 million in 2038 . Emergency is a health problem that is common in elderly today. Apart from acute illnesses, chronic diseases, or geriatric syndromes, emergency illnesses can cause the elderly to become dependent or can lead to premature death. Based on statistical data reported during the year 2012-2015 of the Emergency Medical Institution of Thailand [1], the number of emergency illnesses increased annually from 1.1 million in 2012 to 1.3 million in 2015, 65 percent of all emergencies is caused by acute illnesses and 35 percent is caused by accidents. In addition, the deaths of the elderly who are emergency patients outside the hospital tend to increase every year [2][3]. It was found that there were elderly deaths before receiving emergency services in 1,436 cases in 2013 and it increased to 1,786 cases in 2016. Although the number of elderly patients who died before the arrival of an ambulance squad to the scene (Response Time) within 8 minutes or more than 8 minutes after receiving an incident report from an elderly patient increases every year, the number of the deaths of critical elderly patients is more related to ambulance squads that spend more than 8 minutes to arrive at a scene than the number of deaths of such cases where the ambulance squad responds within 8 minutes. The development of an emergency medical system to be effective is essential to save lives and reduce the loss, including the disability of an emergency patient. The development of a system requires planning that is ready in all aspects of knowledge, personnel and equipment, including the technology to be used cost-effectively and efficiently. Previously, the National Reform Steering Committee on Public Health and Environment, and the National Reform Steering Assembly have established the Emergency Medical Institution as the main agency for establishing a single number emergency call center, and the Ministry of Education to put contents about first aid, basic resuscitation, and road safety in the curriculum of secondary education. The National Reform Steering Assembly has also created the Organization of Local Administration to operate and manage emergency medical services outside of hospitals in the local area [6]. Besides, an Out-of-hospital emergency operations guide has been developed for all levels to guide the practice of medicine that must be under the supervision of a medical professional staff and as a guide for medical practitioners to supervise emergency operators who are not medical professionals [4][5].

Therefore, a mobile system of volunteers for the prehospital emergency service is developed to assist medical emergencies for the elderly in urban communities through the association of the Organization of Local Administration and to 
develop the capacity of emergency volunteers in the area to be able to provide pre-hospital treatment when an elderly person is in an emergency situation. That can reduce the effects of a severe illness that results in the elderly becoming dependent or in a subsequent death. In addition, we proposed prehospital emergency system called A-SA SOS which consisted of four systems: the A-SA SOS Rescuer application, the A-SA SOS elderly application, the A-SA SOS Smart device and the A-SA SOS pre-hospital data control center.

This research is organized as follows: Section I and II covers the introduction and the related works of the prehospital emergency system. In section III we propose the system architecture of the pre-hospital emergency system. Then, we evaluate the results of our proposed system in section IV. Finally, in section V, VI we summarize our research and discuss the future work.

\section{RELATED WORKS}

Mobile devices are present everywhere. Almost all of them have a computing power that is similar to a personal computer but their price is much lower. Their lightness is beneficial to various researchers for utilizing them to improve the effectiveness of rescue operations [7]. For instance, there is a mobile application created to aid PEMS officials to convey to patients with hearing loss [8]. They utilize mobile devices to develop the system form for testing the rescue operations' effectiveness [9]. There is an electronic note system developed for tablets used to record pre-hospital patient care [10].

The application called Emergency Medical Centre Locator (EMCL) is developed to assist patients in finding the nearest specialized emergency medical center. There are six specific sections that the application emphasizes, including injury, eye, cardiac, stroke, burn, and pediatric. This application is not available for Android, only available for iOS systems. Even though its name and description seem like it can help the patient find the nearest specialized emergency medical center, the application does not work based on this method. It allows the patient to find all the medical centers that appear and choose the place that is nearby and appropriate for the patient's emergency case. Actually, this application's function might not be good enough to be used in an emergency situation because of its inconvenience and because it takes too much time for a patient who requires instant help. Nonetheless, there is no genuine emergency help given as this application does not offer any facilitations to a patient emergency call for rescue and is unable to convey to physician [13].

A model has been developed with the purpose of supporting senior citizens' healthcare and handicapped people. The model is grounded on personal-centric sensing structure. It offers the elderly and handicapped people with the service that serves for emergency responsiveness when there is an uncommon health condition [12].

Pre-hospital Emergency Notification System has been developed for mobile platforms to enable the emergency medical officials to notify a team in the hospital about individual information of the incoming casualty and about the seriousness of injuries of road accidents. Moreover, the system is able to let the hospital officials learn about the information of the incoming injuries. Pre-hospital Emergency Notification System has been created for a mobile application, using 2 inventor apps, such as MYSQL and PHP [14].

There is a system created to assist the elderly to locate any nearby medical place simply by using the information of a mobile GPS locality along with access point. Furthermore, they can observe users with a Bluetooth beacon. Hence, the system will automatically evaluate users' present coordinates with the GPS or the information of a network system. This means that the system can locate any nearby medical centers or clinics from the database that stores the information about the medical places' location [11].

\section{THE PRoposed SYSTEM}

\section{A. A-SA SOS Users}

The A-SA SOS users are categorized into four types of participants: elderly with smartphone, elderly with SOS smart device, Village Health Volunteers (VHV), A-SA SOS officer. In addition, the term "elderly with smartphone" refers to elderly people who are familiar with using smartphones and need medical emergency request for the rescue. "Participants with SOS smart devices" refers to the elderly who are using the SOS smart device instead of smartphone. "Village Health Volunteers" (VHV) is a participating group who takes care of the health of people in rural areas. A-SA SOS officer is the person who manages the overall functioning of the system for the elderly and the Village Health Volunteers.

\section{B. System Architecture}

The A-SA SOS application aims to improve the prehospital emergency service for people living in urban cities. The system architecture of A-SA SOS is shown in Fig 5. As we mentioned before, there are four types of actors in the system. For each actor, we proposed three system architectures in order to improve the pre-hospital emergency service, namely, A-SA SOS Rescuer application, A-SA SOS elderly application and A-SA SOS pre-hospital data control center. The details of each system can be described as follows:

1) A-SA SOS Rescuer application is focused on the Village Health Volunteer user around rural areas near the elderly people and it performs several functions as follows: First, it receives the emergency rescue request from the A-SA SOS elderly application via a cloud server then it uses the elderly geo location to reach for a first aid and rescue operation. Second, it enables to contact and point out the elderly location and forwards it to medical equipment transporters near the emergency site in serious cases. Third, the application reports on the progress of the rescue situation and transfers the elderly information to the A-SA SOS prehospital center then the system contacts the hospital which is suitable for the elderly. The A-SA SOSRescuer application is shown in fig 1 . 


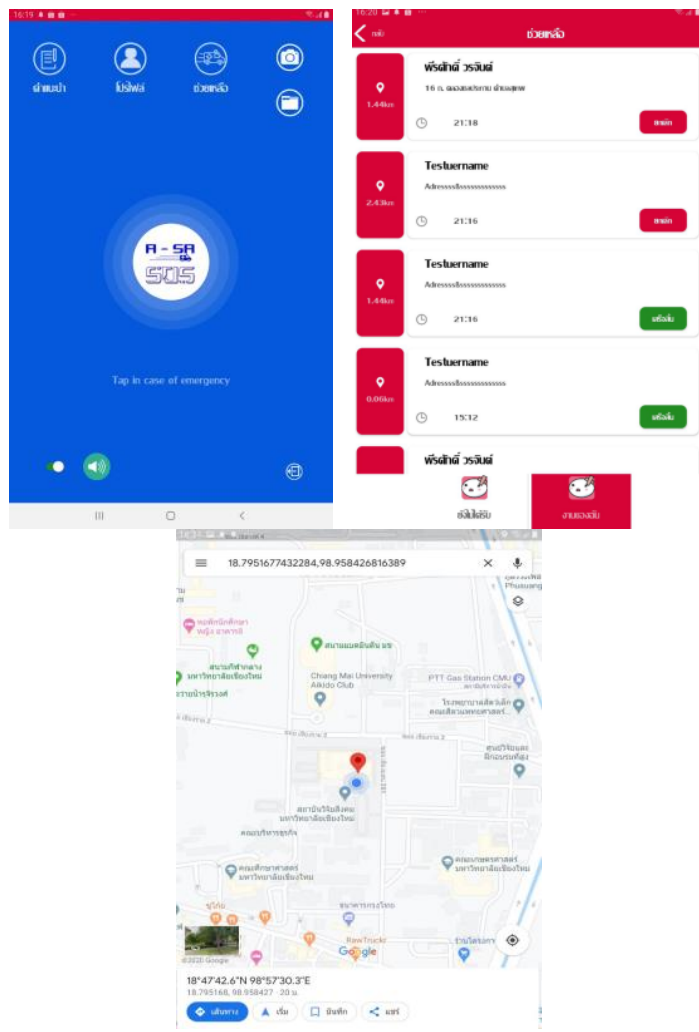

Fig. 1. A-SA SOS Rescuer Application.

2) A-SA SOS elderly application is proposed to mainly focus on the elderly of traumatic and non-traumatic cases who live at home alone or are bedridden. The application consists of two types of rescuer platform.

a) A-SA SOS mobile application: This platform is designed for elderly who are familiar with using smartphone applications. The application was developed to send the rescuer request together with the geoinformation of the user, and it is designed to have only one button on the user interface.The application was developed by the Xamarin cross platform version 4.2 and it sends data to the cloud server by JSON data format via https protocol. The A-SA sos application is shown in Fig. 2.

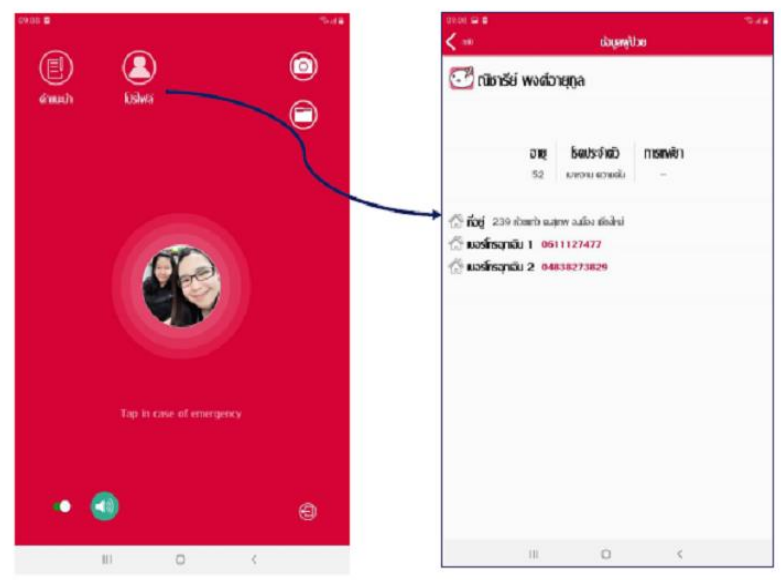

Fig. 2. A-SA SOS Mobile Application on Android os for Patients. b) A-SA SOS Smart device: The IoT-based platform for smart device is designed for the elderly who don't use a smartphone. For this case, we developed a smart device based on an arduino with $4 \mathrm{G}$ sim card which sends data to the cloud server by MQTT protocol. The device is designed with one button on the center of the device in order to be usable in case of an accident. The A-SA SOS smart device is shown in fig 3.

c) A-SA SOS officers and the Resuscitation team: This web-based platform is to support the back-office for the A-SA SOS officers. In terms of the management system, we designed a system based on corporate management among elderly people, Village Health Volunteers and the Resuscitation team in order to manage the emergency cases of the elderly until it is confirmed that they accessed pre-hospital service.
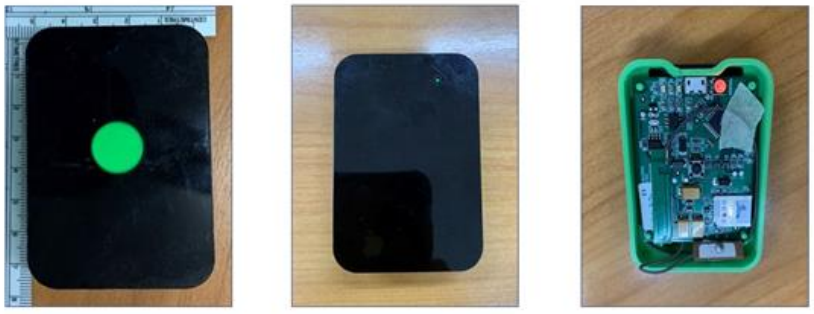

Fig. 3. A-SA SOS Smart Device.

d) A-SA SOS pre-hospital data control center: The core system of the pre-hospital support center was developed based on the cloud server consisting of three modules: First, the Broadcasting module is responsible for broadcasting the elderly information while they are in need of being rescued by Village Health Volunteers. Second, the Web-based Monitor Module is the core data center that computes the possible matches between the elderly and Village Health Volunteers and synchronizes it with the database system. Finally the ASA SOS Management Module is responsible for querying information of all users in the system from the database. The overall system architecture of A-SA SOS is shown in Fig 4.

\section{Procedure Scenario Example}

In this section, we show the scenario of the procedure of how the A-SA SOS system works. The procedure consists of the steps to be followed if an accident or sudden illness occurs

1) The elderly pushes the rescue button of the application or the button of the smart device in case the user is not familiar with the smartphone, in order to call for rescue.

2) The data from the application or device used by elderly is sent to the cloud server then the Web-based Monitor Module is computed for the top ten list of Village Health Volunteers who are located near to the elderly.

3) The Web-based Monitor Module computes the distance between the geo-location of the elderly and that of all the Village Health Volunteers by the Haversine formula[15]. The equation (1) is described below.

$$
d=2 r \arcsin \left(\sqrt{\sin ^{2}\left(\frac{\emptyset_{2}-\emptyset_{1}}{2}\right)+\cos \left(\emptyset_{2}\right) \cos \left(\emptyset_{2}\right) \sin ^{2}\left(\frac{\lambda_{2}-\lambda_{1}}{2}\right)}\right)
$$


where

$\emptyset_{1}, \emptyset_{2}$ are the latitude of point 1 and latitude of point 2( in radians)

$\lambda_{1}, \lambda_{2}$ are the longitude of point 1 and longitude of point 2 (in radians)

We filter the list of Village Health Volunteers to those not further then 1.5 kilometres and create a priority list of not more than ten volunteers. Then, the broadcast module sends the emergency case to the A-SA SOS Rescuer application.

4) In this step, the Village Health Volunteer who uses the A-SA SOS Rescuer application receives a notification of the geo-information of the elderly. Thena matching between a Village Health Volunteer and the elderly is made depending on who pushed on the system first.

Please note that, in case the system is unable to make a matching to rescue the elderly within three minute two times in row then the resuscitation team or 1669 is responsible for the case.

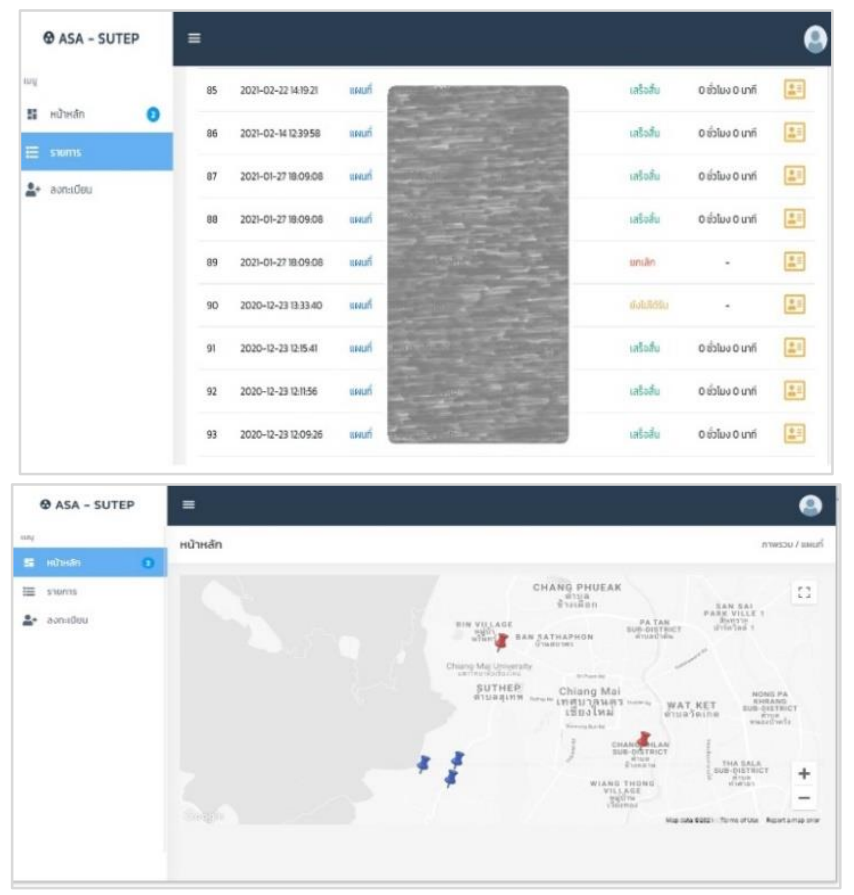

Fig. 4. A-SA SOS Officers and Resuscitation Team.

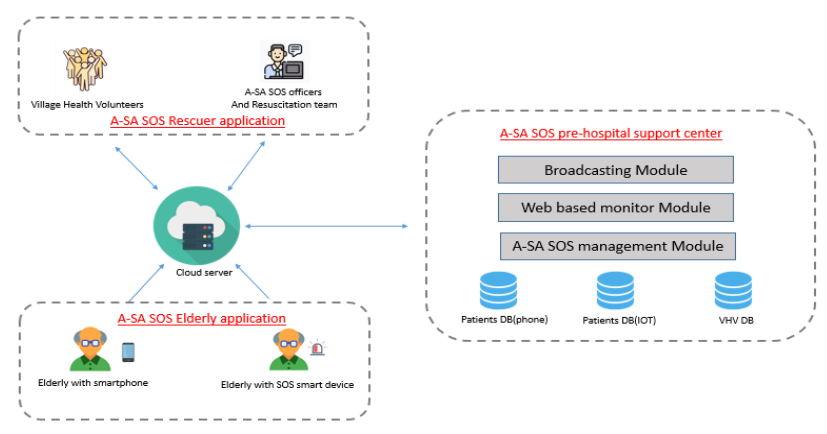

Fig. 5. A-SA SOS System Architecture.

5) Next, the Village Health Volunteer reaches the eldery and gives first aid. Then symptoms are assessed and forwarded to the resuscitation team or 1669 in serious cases
From the procedure scenario f example, it can be seen how the elderly can benefit from our approach by using the A-SA SOS system. When an elderly person gets in an accident she can immediately contact the nearest village Health Volunteers and the resuscitation team or 1669. Also, officers can get all the information needed to rescue the elderly from the application. Most importantly, all these procedures can drastically reduce the operation time and greatly increases the survival rate of the elderly.

\section{EXPERIMENT AND RESULTS}

This section shows the evaluation of our experiment and the result of the proposed A-SA SOS system. To evaluate the outcome, we carried out a pilot test of the A-SA SOS system in real situation for three months in the Sub-district of Suthep in Chiang Mai city. There were 236 participants totally,with 171 female $(74.34 \%)$ and 59 male $(25.65 \%)$ participants. From all the participants, there were 30 elderly who used the A-SA SOS Smart device. The statistics of the total number of time for using the emergency of our proposed system is shown in table 1 .

From the usage of a medical emergency rescue system for the elderly in Suthep, Mueang, Chiang Mai, between August 1 - October 31, 2020, it was found that the emergency operations of Suthep Sub-District Municipality totally sent a medical emergency rescue for 226 times. Most of service users were under aged 60, total of 170 times, 45 times were elderly patients over 60 , and 11 times were unable to specify their age. For the elderly, 62.22\% were female and $77.78 \%$ lived in Suthep Sub-District Municipality.There were five causes of emergency medical services, including 1) illness, fatigue (non-specific) $22.22 \%, 2$ ) Dyspnea $17.78 \%$, 3) fall, accident, pain $15.56 \%$, 4) cardiac arrest $11.11 \%$ and 5) unconsciousness, unresponsiveness, faint $11.11 \%$. For the duration of the operation, it was found that the incident report time to the order time took $0.31 \pm 0.09$ minutes, the incident report time to departure time took $4.60 \pm 0.64$ minutes, and the incident report time to a scene took $4.91 \pm 0.56$. Minutes (Table 1).

TABLE I. THE TOTAL USAGE TIME OF THE EMERGENCY OF OUR PROPOSED SYSTEM

\begin{tabular}{|c|c|c|c|c|}
\hline \multirow{2}{*}{ Information } & \multicolumn{2}{|c|}{ Age $>60$ years } & \multicolumn{2}{|c|}{ Age $<60$ years } \\
\hline & Number & Percentage & Number & Percentage \\
\hline \multicolumn{5}{|l|}{ Gender } \\
\hline Male & 17 & 37.78 & 87 & 51.18 \\
\hline Female & 28 & 62.22 & 83 & 48.82 \\
\hline \multicolumn{5}{|l|}{ Symptoms } \\
\hline $\begin{array}{l}\text { stomachache, } \\
\text { backache, pelvis, } \\
\text { and groin pain }\end{array}$ & 1 & 2.22 & 10 & 5.88 \\
\hline $\begin{array}{l}\text { Anaphylaxis and } \\
\text { allergic reaction }\end{array}$ & 0 & 0 & 7 & 4.12 \\
\hline animal bite & 0 & 0 & 0 & 0 \\
\hline $\begin{array}{l}\text { bleeding } \\
\text { (without injury) }\end{array}$ & 0 & 0 & 2 & 1.18 \\
\hline Dyspnea & 8 & 17.78 & 5 & 2.94 \\
\hline
\end{tabular}




\begin{tabular}{|c|c|c|c|c|}
\hline Cardiac arrest & 5 & 11.11 & 2 & 1.18 \\
\hline Angina Pectoris & 0 & 0 & 2 & 1.18 \\
\hline choking & 0 & 0 & 0 & 0 \\
\hline Diabetes & 1 & 2.22 & 1 & 0.59 \\
\hline $\begin{array}{l}\text { environmental } \\
\text { health hazards }\end{array}$ & 0 & 0 & 0 & 0 \\
\hline wounded & 1 & 2.22 & 1 & 0.59 \\
\hline $\begin{array}{l}\text { headache, sore } \\
\text { throat }\end{array}$ & 0 & 0 & 1 & 0.59 \\
\hline $\begin{array}{l}\text { Manic episode, } \\
\text { neurosis, temper }\end{array}$ & 1 & 2.22 & 11 & 6.47 \\
\hline $\begin{array}{l}\text { overdose, } \\
\text { poisoning }\end{array}$ & 0 & 0 & 7 & 4.12 \\
\hline $\begin{array}{l}\text { pregnancy, } \\
\text { delivery, } \\
\text { gynecology }\end{array}$ & 0 & 0 & 0 & 0 \\
\hline seizures & 0 & 0 & 2 & 1.18 \\
\hline $\begin{array}{l}\text { illness, fatigue } \\
\text { (non-specific) etc. }\end{array}$ & 10 & 22.22 & 18 & 10.59 \\
\hline $\begin{array}{l}\text { limb weakness, } \\
\text { Dysarthria, } \\
\text { crooked- mouth }\end{array}$ & 4 & 8.89 & 5 & 2.94 \\
\hline $\begin{array}{l}\text { unconsciousness, } \\
\text { unresponsiveness, } \\
\text { faint }\end{array}$ & 5 & 11.11 & 7 & 4.12 \\
\hline $\begin{array}{l}\text { child, infant } \\
\text { (Pediatrics) }\end{array}$ & 0 & 0 & 0 & 0 \\
\hline injured & 1 & 2.22 & 24 & 14.12 \\
\hline $\begin{array}{l}\text { burn (hotness), } \\
\text { electricity, } \\
\text { chemical }\end{array}$ & 0 & 0 & 0 & 0 \\
\hline $\begin{array}{l}\text { drowning, diving } \\
\text { injury, water } \\
\text { injury accidents }\end{array}$ & 0 & 0 & 0 & 0 \\
\hline fall, accident, pain & 7 & 15.56 & 37 & 21.76 \\
\hline $\begin{array}{l}\text { Motor vehicle } \\
\text { accident injury }\end{array}$ & 1 & 2.22 & 28 & 16.47 \\
\hline Operating area & & & & \\
\hline $\begin{array}{l}\text { In Suthep Sub- } \\
\text { district } \\
\text { Municipality }\end{array}$ & 35 & 77.78 & 134 & 78.82 \\
\hline $\begin{array}{l}\text { Outside Suthep } \\
\text { Sub-district } \\
\text { Municipality }\end{array}$ & 10 & 22.22 & 36 & 21.18 \\
\hline $\begin{array}{l}\text { Time of } \\
\text { operation }\end{array}$ & & & & \\
\hline $\begin{array}{l}\text { Incident report } \\
\text { order time } \\
\text { (minute) }\end{array}$ & \multicolumn{2}{|l|}{$0.31 \pm 0.09$} & \multicolumn{2}{|l|}{$0.24 \pm 0.04$} \\
\hline $\begin{array}{l}\text { Incident report } \\
\text { departure time } \\
\text { (minute) }\end{array}$ & \multicolumn{2}{|l|}{$4.60 \pm 0.54$} & \multicolumn{2}{|l|}{$5.22 \pm 0.59$} \\
\hline $\begin{array}{l}\text { Incident report } \\
\text { time to arrive at } \\
\text { scene (minute) }\end{array}$ & \multicolumn{2}{|l|}{$4.91 \pm 0.56$} & \multicolumn{2}{|l|}{$5.46 \pm 0.56$} \\
\hline
\end{tabular}

\section{DISCUSSION}

From the results of this study, it can be concluded that the application of the medical emergency rescue system for the elderly in urban communities has been used to help the elderly report emergencies effectively and quickly and emergency rescuers could also reach the scenes faster. The medical emergency rescue system includes 1) A-SA SOS elderly application and smart devices were developed for the elderly to report emergency incidents. After reporting an emergency incident, the device sends signals via cellular wireless communication and notifies the location, and sends information to the emergency volunteer application (A-SA SOS Rescuer application) and the emergency volunteer center (A-SA SOS officers and Resuscitation team:). According to the device usage of the elderly for 3 months, it was found that the developed devices may be difficult to use for the elderly in terms of convenience, as the batteries last for approximately 15 hours, which must be recharged every day before the battery runs out. If the battery is completely discharged, the device must be turned on again. 2) The emergency volunteer application (A-SA SOS Rescuer application) is an application used for reporting and receiving emergency reports for general citizens and community emergency volunteers. This application is available only on the Android system, not on the IOS system. When evaluating the possibility of using the app, it can notify the incident time more quickly because the app will send signals to the application of a person directly and can tell the location of the emergency scene. 3) From the rehearsal of the aid system that has been developed, it was found that the incident report time to the order time was less than 1 minute, which was compatible with the standards of the National Institute of Emergency Medicine. Finally, the reported average time to arrive at a scene $(4.91 \pm 0.56)$ when helping elderly patients was less than the standard specified criteria of 8 minutes with an average of 3 minutes.

\section{CONCLUSION AND Future ReSEARCH}

In this research, we proposed the A-SA SOS system which consisted of a mobile and IoT-based healthcare application for the pre-hospital medical emergency rescue system for the elderly in urban communities. The main contribution of this research is to provide an effective management tool for the Village Health Volunteers to accelerate and improve the reach of elderly in order to give faster first aid during an emergency situation. In terms of evaluation of the system, we tested the A-SA SOS system for three months in the Sub-district of Sutep in Chiang Mai city. There were 226 medical emergency rescue cases in total and according to the incident report the average time to arrive at a scene was $(4.91 \pm 0.56)$ when helping elderly patients which was 3 minutes less in average than the standard criteria.

In the future work, we first plan to improve the A-SA SOS Smart device in terms of convenience such as usability and extended battery lifetime. Second, we would like to test the system in the wider area of Chiang Mai and for a longer period than 3 months. Third, we plan to improve the application A-SA SOS Rescuer application to develop the automatic rescue request notification using a messaging platform API such as LINE, Facebook to provide health volunteers with more convenience when receiving elderly calls in emergency situations. 


\section{ACKNOWLEDGMENT}

This work was supported by the National Research Council of Thailand (NRCT).

\section{REFERENCES}

[1] Prasartkul, P., Rittirong, J., Chuanwan, S., Kanchanachitra, M., Katewongsa, P., \& Thianlai, K. (2015). Situation of the Thai elderly. Nakhon Pathom: Institue for Population and Social Research Mahdiol University.

[2] Sukkird, V., \& Shirahada, K. (2018). E-health service model for Asian developing countries: A case of emergency medical service for elderly people in Thailand. In Optimizing Current Practices in E-Services and Mobile Applications (pp. 214-232). IGI Global.

[3] Shatpattananunt, B., Wiangosot, S., \& Pintatham, K. (2018). Elderly patients' experience in using emergency medical service at a tertiary hospital, upper northern Thailand. Songklanagarind Journal of Nursing, 38(3), 102-115.

[4] Smith, C. M., Wilson, M. H., Ghorbangholi, A., Hartley-Sharpe, C., Gwinnutt, C., Dicker, B., \& Perkins, G. D. (2017). The use of trained volunteers in the response to out-of-hospital cardiac arrest-the GoodSAM experience. Resuscitation, 121, 123-126.

[5] Vattanavanit, V., Uppanisakorn, S., \& Nilmoje, T. (2020). Post out-ofhospital cardiac arrest care in a tertiary care center in southern Thailand: from emergency department to intensive care unit. Hong Kong Journal of Emergency Medicine, 27(3), 155-161.

[6] Pudpong, N., Durier, N., Julchoo, S., Sainam, P., Kuttiparambil, B., \& Suphanchaimat, R. (2019). Assessment of a voluntary non-profit health insurance scheme for migrants along the Thai-Myanmar border: a case study of the migrant fund in Thailand. International journal of environmental research and public health, 16(14), 2581.
[7] Toahchoodee, M. (2017, July). ARSA-the pervasive Rescuer Supporting System for the Pre-Hospital Emergency Medical Service. In 2017 14th International Joint Conference on Computer Science and Software Engineering (JCSSE) (pp. 1-6). IEEE.

[8] F. Buttussi, L. Chittaro, E. Carchietti, and M. Coppo, "Using mobile devices to support communication between emergency medical responders and deaf people," in Proceedings of the 12th International Conference on Human Computer Interaction with Mobile Devices and Services, ser. MobileHCI '10. New York, NY, USA: ACM, 2010, pp. 716. [Online]. Available: http://doi.acm.org/10.1145/1851600.1851605

[9] K. Nakata, K. Maeda, T. Umedu, A. Hiromori, H. Yamaguchi, and T. Hi-gashino, "Modeling and evaluation of rescue operations using mobile communication devices," in 2009 ACM/IEEE/SCS 23rd Workshop on Principles of Advanced and Distributed Simulation, June 2009, pp. 64 71.

[10] A. F. Duarte, H. V. Cesar, A. L. M. Marques, P. M. d. A. Marques, and G. A. P. Junior, "Prehospital electronic record with use of mobile devices' in the samu's ambulances in ribeirao preto-brazil," in 2015 IEEE 28th International Symposium on Computer-Based Medical Systems, June 2015, pp. 362-363.

[11] Huh JH, Kim TJ (2018) A location-based mobile health care facility search system for senior citizens. The Journal of Supercomputing

[12] Hussain A, Wenbi R, da Silva AL, Nadher M, Mudhish M (2015) Health and emergency-care platform for the elderly and disabled people in the Smart City. Journal of Systems and Software

[13] Moskowitz (2014) LLC emergency medical center locator. Available at: www.itunes.apple.com

[14] A. Sarlan, F. K. Xiong, R. Ahmad, W. F. W. Ahmad and E. Bhattacharyya, "Pre-hospital emergency notification system," 2015 International Symposium on Mathematical Sciences and Computing Research (iSMSC), Ipon, 2015, pp. 168-173.

[15] Robusto, C. C. (1957). The cosine-haversine formula. The American Mathematical Monthly, 64(1), 38-40. 